\title{
Spectroscopic, Characterization and Biological Studies of Pyridine Carboxyamide Complexes
}

\author{
BIBHESH K.SINGH ${ }^{1}$, HEMANT K. RAJOUR ${ }^{2}$, \\ REKHA CHAUHAN $^{1}$ and SAURABH GOYAL ${ }^{1}$ \\ ${ }^{1}$ Department of Chemistry, Govt. Postgraduate College, Ranikhet, \\ Uttarakhand-263645, India \\ ${ }^{2}$ Department of Chemistry, Ramjas College, University of Delhi, Delhi-110007, India \\ bibheshksingh@yahoo.co.in
}

Received 13 March 2015 / Accepted 18 April 2015

\begin{abstract}
Newly synthesized carboxyamide ligand $N, N^{\prime}$-bis(2-carboxy-1-oxophenelenyl) pyridine 2,6- diamine and their $\mathrm{Co}(\mathrm{II}), \mathrm{Ni}(\mathrm{II})$ and $\mathrm{Cu}(\mathrm{II})$ complexes have been synthesized and characterized by various physicochemical techniques. Vibrational spectra indicate coordination of amide and carboxylate oxygen of the ligand. Mass spectrum explains the successive degradation of the molecular species in solution and justifies ML complexes. The electron paramagnetic resonance of the $\mathrm{Cu}(\mathrm{II})$ complex shows $\mathrm{g}_{\|}>\mathrm{g}_{\perp}>2.03$ was observed indicated that unpaired electron most likely reside in the $\mathrm{dx}^{2}-\mathrm{y}^{2}$ ( or less likely a $\mathrm{d}_{\mathrm{xy}}$ ) ground state, which is consistent with the proposed square based geometry. Electronic spectra and magnetic susceptibility measurements reveal square planar geometry for metal complexes. Molecular structure of the complexes has been optimized by $\mathrm{MM}^{+}$calculations and supports a square planar geometry. The bio-efficacy of the ligands and its metal complexes has been examined against the growth of bacteria in vitro to evaluate their anti-microbial potential.
\end{abstract}

Keywords: Bioactivity, Carboxyamide, Complexes, Spectra, Molecular modeling

\section{Introduction}

The continuing interest in the study of amide complexes derives from their ability to model active sites present in some metalloproteins ${ }^{1}$ and the search for a better understanding of the physicochemical properties of such complexes, especially the stereochemistry of the metallic center ${ }^{2}$. The metal-induced cleavage of carboxyamide is a well-established reaction. Its importance in hydrolytic enzymes ${ }^{3}$ inspired sophisticated biomimetic applications such as the site- selective cleavage of peptide by synthetic palladium complexes ${ }^{4}$. The carboxyamide $[-\mathrm{C}(\mathrm{O}) \mathrm{NH}-]$ group, ubiquitous throughout nature in the primary structure of proteins, which has attracted much attention because it can provide models from the standpoint of bioinorganic chemistry ${ }^{5}$. Consequently, the behavior of pyridine carboxyamide containing this linkage, towards biologically relevant metals has been widely investigated ${ }^{6}$. This is because pyridine carboxyamide ligand contains lipophilic group of aromatic ring and 
hydrophilic group of carboxyamide. The lipophilic group can make drugs more capable of penetrating through cell membrane to bind to the target DNA and the hydrophilic group can reduce toxicity from the drugs. In this case, linear ligand systems based upon pyridine carboxyamide are very useful to modulate the structural and electronic properties of firstrow transition metal centers. It was demonstrated that electronically or sterically demanding pyridine amide ligands can dictate the geometry and coordination number of such complexes ${ }^{7}$. These ligands have been considered as model compounds for the study of the effects of intramolecular and intermolecular hydrogen bonding ${ }^{8}$. Pyridine carboxaldehyde ligands have found use in asymmetric catalysis ${ }^{9}$, dendrimer synthesis ${ }^{9}$ and gold(III) and platinum(II) complexes with antitumor properties ${ }^{10}$.

In well understood cases, the amide bond is activated by coordination of the carbonyl oxygen atom to the metal center. However, the coordination of an electrically neutral nitrogen atom in metal complexes of carboxamide is an alternative that has gained little attention. Though much work has been done on amide ligands in general and the amide ligands in combination with other functional groups, only less work has been done on the amide system containing carboxylic anchors, which may act as biomimic to peptide and certain enzymes. Ligands containing carboxyamide chains having $\mathrm{O}_{4}$ donor atoms, and their complexes, have been cited as possessing noteworthy pharmacological activity ${ }^{11}$. The aim of antimicrobial activity was to assess the effect on microbial activities and to contribute a better understanding of the antimicrobial activity of the transition metal complexes. In view of the biological significance and diverse coordinating behavior of amide group, its coordination chemistry is complicated and the most definitive information has been obtained by using results from combination of various techniques. In this work, spectral characterization serves as important tools for the interpretation of structures of biomolecules. The present work deals specially the coordination properties of $N, N^{\prime}$-bis(2-carboxy-1-oxophenelenyl) pyridine 2,6- diamine concerning its interactions with $\mathrm{Co}(\mathrm{II}), \mathrm{Ni}(\mathrm{II})$ and $\mathrm{Cu}(\mathrm{II})$. The bio-efficacy of these complexes has been examined against the growth of bacteria in vitro to evaluate their anti-microbial potential.

\section{Experimental}

All the chemicals used were of analytical grade and used as procured. Solvents used were of analytical grade and were purified by standard procedures. The stoichiometric analyses (C, $\mathrm{H}$ and $\mathrm{N}$ ) of the complexes were performed using Elementar vario EL III (Germany) model. Metal contents were estimated on an AA-640-13 Shimadzu flame atomic absorption spectrophotometer in solution prepared by decomposing the respective complex in hot concentrated $\mathrm{HNO}_{3}$. Their IR spectra were recorded on Perkin-Elmer FT-IR spectrophotometer in $\mathrm{KBr}$ and polyethylene pellets in the range $400-4000 \mathrm{~cm}^{-1}$ and 100 $400 \mathrm{~cm}^{-1}$, respectively. ${ }^{1} \mathrm{H}$ NMR spectra were recorded in DMSO-d $\mathrm{d}_{6}$ solvent (solvent peak $2.5 \mathrm{ppm}$ ) on a Bruker Advance 400 instrument. Proton chemical shifts are reported in parts per million(ppm) relative to an internal standard of $\mathrm{Me}_{4} \mathrm{Si}$. The UV-Visible spectra were recorded in DMSO on Beckman DU-64 spectrophotometer with quartz cells of $1 \mathrm{~cm}$ path length from 200-900nm and mass spectra (TOF-MS) were recorded on Waters (USA) KC455 model with $\mathrm{ES}^{+}$mode in DMSO. X-band EPR spectra were recorded on a Varian E-112 spectrometer with a variable temperature liquid nitrogen cryostat (the error in $g$ value is $\pm 0.001)$ and $g$ factors were quoted relative to the standard marker $\operatorname{TCNE}(\mathrm{g}=2.00277)$. Magnetic susceptibility measurements were carried out at room temperature in powder form on a vibrating sample magnetometer PAR 155 with 5000G-field strength, using $\mathrm{Co}\left[\mathrm{Hg}(\mathrm{SCN})_{4}\right]$ as the calibrant (magnetic susceptibility $\approx 1.644 \times 10^{-5} \mathrm{~cm}^{3} \mathrm{~g}^{-1}$ ). 


\section{Synthesis of ligands and complexes}

\section{Synthesis of N,N'-bis(2-carboxy-1-oxophenelenyl) pyridine 2, 6- diamine (Figure 1)}

A finely ground mixture of pyridine 2,6 - diamine $(0.5 \mathrm{mmol})$, phthalic anhydride $(1.0 \mathrm{mmol})$ and fused sodium acetate $(0.5 \mathrm{mmol})$ in glacial acetic acid $(25 \mathrm{~mL})$ was refluxed on a water bath for $3 \mathrm{~h}$. After filtering the residue, filtration on slow evaporation forms fine crystals. These were recrystallized in acetic acid washed with ethanol and dried over $\mathrm{P}_{4} \mathrm{O}_{10}$ in vacuo. Ligand is soluble in common organic solvents.<smiles>O=C(Nc1cccc(NC(=O)c2ccccc2O)n1)c1ccccc1O</smiles>

Figure 1. Structure of ligand

\section{Synthesis of metal complexes}

To a methanolic solution of metal acetate $(0.5 \mathrm{mmol})[\mathrm{M}(\mathrm{II})=\mathrm{Co}(\mathrm{II}), \mathrm{Ni}(\mathrm{II}), \mathrm{Cu}(\mathrm{II})]$ a methanolic solution of the newly synthesized carboxyamide ligands $(0.5 \mathrm{mmol})$ was added in a separate flask. The resulting solution was stirred for $3 \mathrm{~h}$, after which the volume was reduced to half on a warm water bath. The product obtained was washed with a small amount of methanol and air- dried. The above product was dissolved in an excess of warm methanol, and the clear solution was left undisturbed for weeks to give beautiful colored crystals of the complexes. Complexes are soluble in common organic solvents. Various attempts to obtain the single crystals have so far been unsuccessful.

\section{Molecular modeling}

Molecular modeling of the proposed structure of the complexes was performed using HyperChem professional version 7.51 program package. The correct stereochemistry was assured through the manipulation and modification of the molecular coordinates to obtain reasonable low energy molecular geometries. The potential energy of the molecule was the sum of the following terms $(E)=E_{\text {str }}+E_{\text {ang }}+E_{\text {tor }}+E_{\mathrm{vdw}}+E_{\text {oop }}+E_{\text {ele, }}$, where all E's represent the energy values corresponding to the given types of interaction $(\mathrm{kcal} / \mathrm{mol})$. The subscripts str, ang, tor, vdw, oop and ele denote bond stretching, angle bonding, torsion deformation, vanderwaals interactions, out of plain bending and electronic interaction, respectively. The molecular mechanics describe the application of classical mechanics to determination of molecular equilibrium structures. It enables the calculation of the total static energy of a molecule in terms of deviations from reference unstrained bond lengths, angles and torsions plus non bonded interactions. On account of non-bonded interactions and also the chemical sense of each atom, treat the force field as a set of constants that have to be fixed by appeal to experiment or more rigorous calculations. It has been found that offdiagonal terms are usually largest when neighboring atoms are involved, and so we have to take account of non-bonded interactions, but only between next-nearest neighbors.

\section{Biological activity}

In vitro antibacterial activity of the synthesized compounds against Streptococcus, Staph, Staphylococcus aureus and Escherchia coli bacteria were carried out using Muller Hinton Agar media(Hi media). The activity was carried out using paper disc method ${ }^{12}$. Base plates 
were prepared by pouring $10 \mathrm{~mL}$ of autoclaved Muller Hinton agar into sterilized Petri dishes ( $9 \mathrm{~mm}$ diameter) are allowing them to settle. Molten autoclaved Muller Hinton had been kept at $48{ }^{\circ} \mathrm{C}$ was incubated with a broth culture of the Streptococcus, Staph, Staphylococcus aureus and Escherchia coli bacteria and then poured over the base plate. The discs were air dried and placed on the top of agar layer. The plates were incubated for $30 \mathrm{~h}$ and the inhibition zones (mm) were measured around each disc. As the organism grows, it forms a turbid layer, except in the region where the concentration of antibacterial agent is above the minimum inhibitory concentration and a zone of inhibition is seen. The size of the inhibition zone depends upon the culture medium, incubation conditions, rate of diffusion and the concentration of the antibacterial agent. The solutions of all compounds were prepared in doubly distilled water and chloramphenicol was used as a reference.

\section{Results and Discussion}

The synthesized compounds are crystalline, colored, non-hygroscopic, insoluble in water, partially soluble in ethanol but soluble in DMF and DMSO. Satisfactory results of elemental analysis, magnetic studies (Table 1) and spectral studies revealed that the complexes were of good purity. The analytical data of the complexes indicated 1:1 metal to ligand stoichiometry. The conductance measurements show these complexes to be non-electrolytes and the mass spectra indicate their monomeric nature. The analytical and spectroscopic data enables us to predict possible structures. The molecular modeling helps to support the possible geometry of the complexes.

Table 1. Color, reaction yield, elemental analysis and magnetic moment of the ligand and complexes

\begin{tabular}{|c|c|c|c|c|c|c|c|c|c|}
\hline \multirow{2}{*}{$\begin{array}{l}\stackrel{0}{z} \\
\dot{\text { s }}\end{array}$} & \multirow{2}{*}{$\begin{array}{l}\text { Compound/Com } \\
\text { plex (Empirical } \\
\text { formula) }\end{array}$} & \multirow{2}{*}{ Color } & \multirow{2}{*}{ 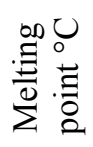 } & \multirow{2}{*}{ 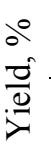 } & \multicolumn{4}{|c|}{ Elemental analysis found/ (calc.) \% } & \multirow{2}{*}{$\begin{array}{c}\mu_{\text {eff }} \\
(\mathrm{BM})\end{array}$} \\
\hline & & & & & $\mathrm{C}$ & $\mathrm{H}$ & $\mathrm{N}$ & M & \\
\hline 1 & $\begin{array}{r}\text { Lig } \\
\left(\mathrm{C}_{21} \mathrm{I}\right.\end{array}$ & $\begin{array}{r}\mathrm{Mu} \\
\text { Bro }\end{array}$ & 280 & 84 & & & & - & - \\
\hline 2 & $\begin{array}{c}{[\mathrm{Co} \mathrm{L}](\mathrm{I})} \\
\left(\mathrm{CoC}_{21} \mathrm{H}_{13} \mathrm{~N}_{3} \mathrm{O}_{6}\right)\end{array}$ & Green & 110 & 89 & $\begin{array}{c}54.51 \\
(54.56)\end{array}$ & $\begin{array}{c}2.78 \\
(2.83)\end{array}$ & $\begin{array}{r}9.1 \\
(9.1\end{array}$ & $\begin{array}{c}12.71 \\
(12.75)\end{array}$ & 2.76 \\
\hline 3 & $\begin{array}{c}{[\mathrm{Ni} \mathrm{L}](\mathrm{II})} \\
\left(\mathrm{NiC}_{21} \mathrm{H}_{13} \mathrm{~N}_{3} \mathrm{O}_{6}\right)\end{array}$ & Brown & 120 & 81 & $\begin{array}{c}54.54 \\
(54.59)\end{array}$ & $\begin{array}{c}2.80 \\
(2.84)\end{array}$ & $\begin{array}{c}9.01 \\
(9.09)\end{array}$ & $\begin{array}{c}12.64 \\
(12.70)\end{array}$ & $\begin{array}{l}\text { Diama } \\
\text { gnetic }\end{array}$ \\
\hline 4 & $\begin{array}{c}{[\mathrm{Cu} \mathrm{L}](\mathrm{III})} \\
\left(\mathrm{CuC}_{21} \mathrm{H}_{13} \mathrm{~N}_{3} \mathrm{O}_{6}\right)\end{array}$ & Black & 110 & 82 & $\begin{array}{c}54.00 \\
(54.02)\end{array}$ & $\begin{array}{c}2.76 \\
(2.81)\end{array}$ & $\begin{array}{c}9.02 \\
(9.00)\end{array}$ & $\begin{array}{c}13.58 \\
(13.61)\end{array}$ & 1.74 \\
\hline
\end{tabular}

Spectroscopic studies and magnetic studies

The ${ }^{1} \mathrm{H}$ NMR spectra of the ligand in DMSO shows well resolved signals as expected (Figure 2: ${ }^{1} \mathrm{H}$ NMR spectrum of the ligand). The $\mathrm{N}-\mathrm{H}$ proton of amide (-CO-NH group) undergoes very rapid exchange with the solvent and appears as a broad ragged doublet around 8.01- $8.13 \mathrm{ppm}$. The spectrum of the ligand shows a singlet peak 10.1-10.4 ppm for$\mathrm{NH}$ group ${ }^{13}$. It has been found that the peak in the region $10.70-10.73 \mathrm{ppm}$ for $-\mathrm{OH}$ group and the $-\mathrm{COOH}$ signal is found in the region 9.90-9.95 ppm in the spectrum of the ligand $^{13,14}$. This signal is completely disappeared in the spectrum of $\mathrm{Ni}(\mathrm{II})$ complex indicating involvement of the $\mathrm{COOH}$ group in chelation through deprotonation of the $\mathrm{COOH}$ group. The peaks in the region $7.0-7.9 \mathrm{ppm}$ were assigned chemical shifts for the hydrogen of the aromatic ring of the ligand. 


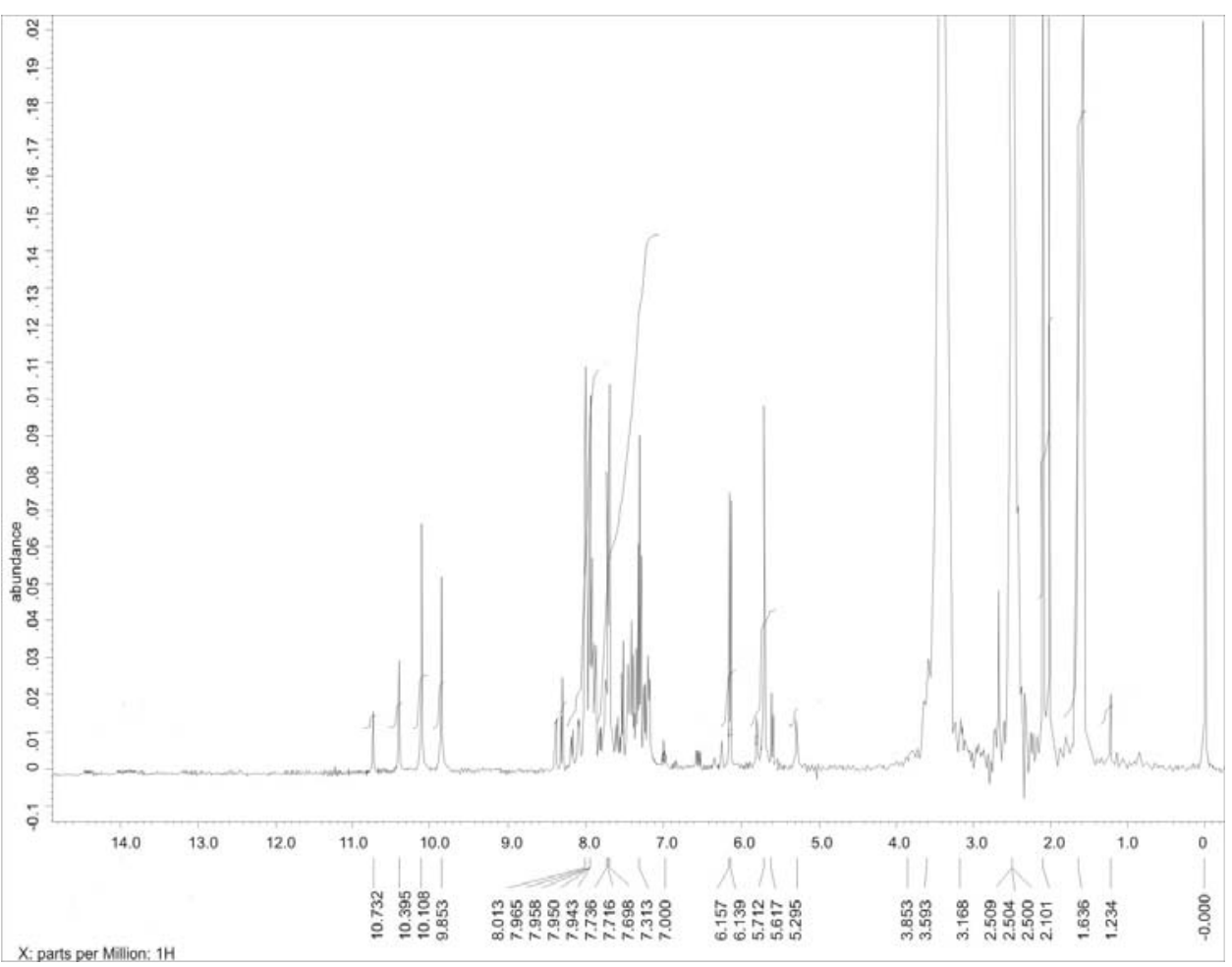

Figure 2. ${ }^{1} \mathrm{H}$ NMR spectrum of the Ligand

An ambidentate nature of the amide can coordinate with metal ion either through nitrogen of the $-\mathrm{NH}$ or the oxygen of the $\mathrm{C}=\mathrm{O}$ group ${ }^{15}$ can be explained with vibrational spectra. The bands due to the amide $v(\mathrm{~N}-\mathrm{H})$ mode at $3300-3400 \mathrm{~cm}^{-1}$ for the free ligands are shifted towards higher frequencies, while the $v(\mathrm{C}=\mathrm{O})\left(\right.$ Amide I) frequency $\left(1630-1640 \mathrm{~cm}^{-1}\right)$ undergoes shift towards lower frequency $\left(1600-1630 \mathrm{~cm}^{-1}\right)$ in the metal complexes indicating non - involvement of the amide nitrogen and involvement of the carbonyl oxygen atom of amide group in coordination with the metal(II) ion (Table 2: IR spectral data of the ligands and its complexes). This result is explained by the lengthening of the $\mathrm{C}=\mathrm{O}$ bond and shortening of the $\mathrm{C}-\mathrm{N}$ bond which cause the decrease and increase of the frequencies respectively ${ }^{16}$. Amide II (1440-1450 $\mathrm{cm}^{-1}$ in ligands) and Amide III $\left(1300-1310 \mathrm{~cm}^{-1}\right.$ in ligands) bands arising out of $v(\mathrm{C}-\mathrm{N})$ as well as $\delta(\mathrm{N}-\mathrm{H})$ modes (coupled to one another), shift towards higher frequencies $1450-1500 \mathrm{~cm}^{-1}$ and $1310-1375 \mathrm{~cm}^{-1}$, respectively in complexes further confirming the coordination through carbonyl oxygen.

Table 2. Infrared spectral data $\left(\mathrm{cm}^{-1}\right)$ of the Ligand and its metal complexes

\begin{tabular}{|c|c|c|c|c|c|c|c|c|}
\hline $\begin{array}{l}Z \\
\dot{s}\end{array}$ & $\begin{array}{l}\text { Ligand/ } \\
\text { Complex }\end{array}$ & $\begin{array}{l}v(\mathrm{~N}-\mathrm{H}) \\
\text { Amide }\end{array}$ & $\begin{array}{l}v(\mathrm{C}=\mathrm{O}) \\
\text { Amide I }\end{array}$ & $\begin{array}{l}v(\mathrm{C}-\mathrm{N})+(\mathrm{N}- \\
\mathrm{H}) \text { Amide II }\end{array}$ & $\begin{array}{l}v[(\mathrm{~N}-\mathrm{H})+\delta(\mathrm{C}- \\
\mathrm{H})] \text { Amide III }\end{array}$ & $v_{\mathrm{as}}\left(\mathrm{CO}_{2}^{-}\right)$ & $v_{\mathrm{S}}\left(\mathrm{CO}_{2}^{-}\right)$ & $v(\mathrm{M}-\mathrm{O})$ \\
\hline 1 & $\mathrm{~L}$ & $3380(\mathrm{~s})$ & $1640(\mathrm{~m})$ & $1448(\mathrm{~m})$ & $1310(\mathrm{~m})$ & $1567(\mathrm{~s})$ & $1418(\mathrm{~s})$ & - \\
\hline 2 & I & $3432(\mathrm{~s})$ & 1617(m) & 1494(m) & $1355(\mathrm{~m})$ & $1560(\mathrm{~s})$ & 1441(s) & 526 \\
\hline 3 & II & 3443(s) & $1622(\mathrm{~m})$ & $1451(\mathrm{~m})$ & $1359(\mathrm{~m})$ & $1562(\mathrm{~s})$ & $1445(\mathrm{~s})$ & 514 \\
\hline 4 & III & 3393(s) & $1618(\mathrm{~m})$ & $1486(\mathrm{~m})$ & $1371(\mathrm{~m})$ & $1560(\mathrm{~s})$ & $1448(\mathrm{~s})$ & 550 \\
\hline
\end{tabular}


The $v(\mathrm{C}=\mathrm{O})$ and $v(\mathrm{C}-\mathrm{O})$ stretching frequencies in the $1560-1570 \mathrm{~cm}^{-1}$ and $1400-1420 \mathrm{~cm}^{-1}$ region in the uncomplexed ligands have been assigned to $v_{\mathrm{as}}\left(\mathrm{CO}_{2}^{-}\right)$and $v_{\mathrm{s}}\left(\mathrm{CO}_{2}^{-}\right)$modes of the $-\mathrm{COOH}$ group and these bands shows considerable shift in all the complexes (Figure 3: IR spectrum of complex III). A positive and negative shift in complexes indicates a $\Delta v$ enhancement upon complexation and suggests coordination of $-\mathrm{COO}^{-}$groups in a monodentate fashion ${ }^{17}$. Here $\Delta v$ implies the difference between $v_{\mathrm{as}}\left(\mathrm{CO}_{2}^{-}\right)$and $v_{\mathrm{s}}\left(\mathrm{CO}_{2}^{-}\right)$(i.e, asymmetric and symmetric stretching modes respectively). A new band in the 500-540(w) cm ${ }^{-1}$ regions in the spectra of the complexes is assignable to $v(\mathrm{M}-\mathrm{O})^{17}$.

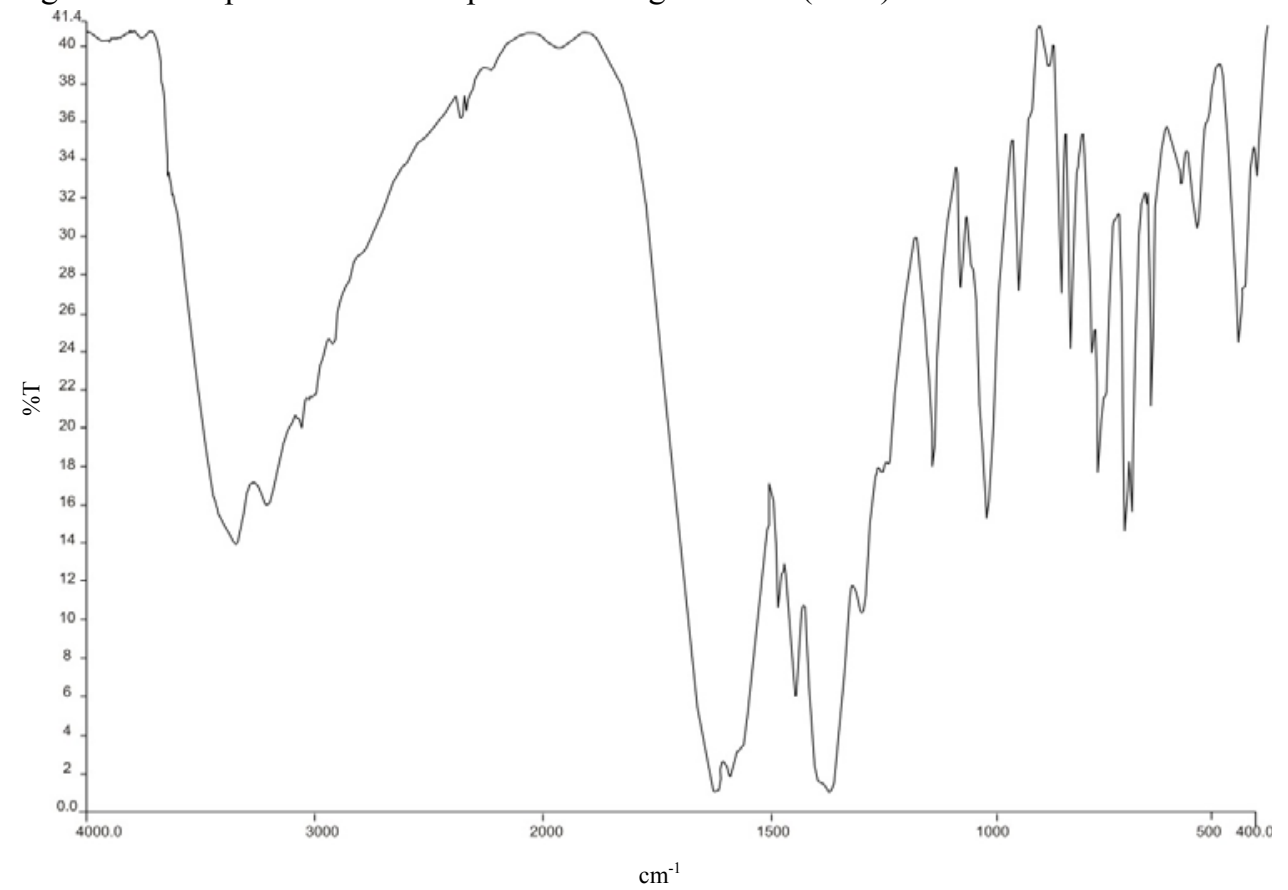

Figure 3. IR spectrum of the complex III

A mass spectrum is particularly useful when a poorly crystalline nature of complexes prevents their X-ray characterization. Mass spectrometry has been successfully used to investigate molecular species in solution ${ }^{18}$. The pattern of the mass spectrum gives an impression of the successive degradation of the target compound with the series of peaks corresponding to the various fragments. The intensity gives an idea of stability of fragments. The mass spectrum of the ligand having molecular ion peaks at $406\{45 \% \mathrm{~m} / \mathrm{z}\}$, confirming purity of the ligand. The ligand has initial loss of two molecules of $\mathrm{HC}=\mathrm{O}]^{+}$with $100 \% \mathrm{~m} / \mathrm{z}$ values and finally forms two molecules of Diamino pyridine $]^{+}$. The recorded molecular ion peaks of the metal complexes have been used to confirm the proposed formula. All the synthesized complexes containing metal ion were confirmed by good agreement between the observed and calculated molecular formula. Elemental analysis values are in close agreement with the values calculated from molecular formulas assigned to these complexes, which further supported by the TOF-mass studies. In the TOF-mass spectra of metal complexes initial fragmentation pattern is again similar, a mononuclear nature for these complexes $[\mathrm{M}(\mathrm{L})]^{+}$can be deduced. The mass spectrum of the complex having a molecular ion peaks confirming the purity of the complexes. All the complexes of ligand at position 
( $\mathrm{m} / \mathrm{z}$ values) $232-234(40 \%$ in all complexes may be due to formation of two molecules of phenyl ring) which could be the result of demetallation and subsequently a partial intramolecular hydrogen bonding. The last two fragments appears in nearly all the complexes at positions $(\mathrm{m} / \mathrm{z}$ values) 216 corresponds to the formation of two molecules of Diamino pyridine $]^{+}$i.e, $\left[\mathrm{C}_{10} \mathrm{H}_{12} \mathrm{~N}_{6}\right]^{+}$and $\mathrm{m} / \mathrm{z}$ values in the range $183-186$ corresponds to the formation of $\left[\mathrm{C}_{10} \mathrm{H}_{10} \mathrm{~N}_{4}\right]^{+}$respectively (Figure 4: TOF-Mass spectrum of complex III). Likewise peaks attributable to unstable monomeric species as $[\mathrm{M}(\mathrm{L})]^{+}$and $\left[\mathrm{H}_{2} \mathrm{~L}\right]^{+}$are usually present in the mass spectra of these systems ${ }^{19}$.

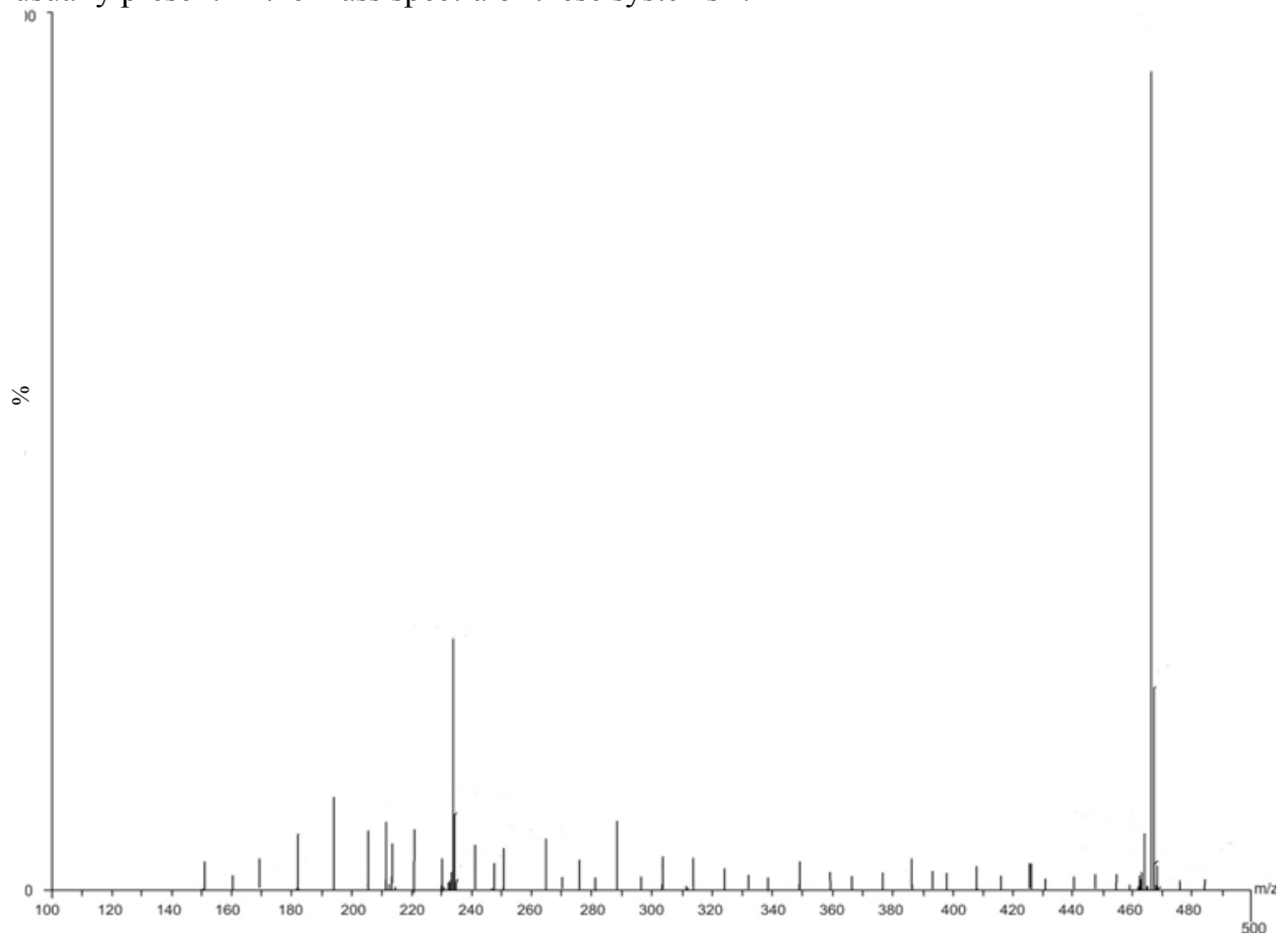

Figure 4. TOF - Mass of complex III

The ligand and their metal complexes show characteristic ultraviolet-visible spectra for the amide and other associated groups. In the ultraviolet region, the shoulder band observed at $286 \mathrm{~nm}$ may be assigned to $\mathrm{n} \rightarrow \mathrm{n} *$ transition within the $\mathrm{C}=\mathrm{O}$ group of the amide moiety in the free ligand. This band is disappeared or bathochromic shift in all the complexes, revealing the involvement of the carbonyl group of the amide or carboxylate oxygen in chelate formation. The band observed at $315 \mathrm{~nm}$ in ligand, may be assigned to the $\pi \rightarrow \pi^{*}$ transition of the $\mathrm{N}$-amino group of the amide, remains at the same position in the metal complexes, indicating they are not affected by metal chelation ${ }^{20}$. The result supports the mode of interaction of amide with transition metal ions. The visible spectrum of cobalt(II) complex show absorption bands at the $540 \mathrm{~nm}$ and $425 \mathrm{~nm}$ assignable to ${ }^{2} \mathrm{~B}_{2 g} \rightarrow{ }^{4} \mathrm{E}_{\mathrm{g}}(\mathrm{P})$ and ${ }^{2} \mathrm{~B}_{2 \mathrm{~g}} \rightarrow{ }^{4} \mathrm{~A}_{2 \mathrm{~g}}(\mathrm{P})$ transitions, suggests square planar geometry of the complex ${ }^{21}$, which is also corroborated by magnetic moment 2.76B.M of the complex. The reason for the departure from the spin only value lies partly in the existence of the second order Zeeman effect between the ground and the higher ligand field terms ${ }^{22}$. However, it lies mainly in the fact that in the presence of spin - orbit coupling, the quenching effect of the ligand field cannot be complete. 
The nickel(II) complex is diamagnetic at room temperature revealing the square planar geometry $^{22}$. The visible spectra of nickel complex shows an absorption band at $642 \mathrm{~nm}$, assignable to a ${ }^{1} \mathrm{~A}_{1 \mathrm{~g}} \rightarrow{ }^{1} \mathrm{~A}_{2 \mathrm{~g}}$ transition and a shoulder around $550 \mathrm{~nm}$ corresponding to a ${ }^{1} \mathrm{~A}_{1 \mathrm{~g}}$ $\rightarrow{ }^{1} \mathrm{~B}_{1 \mathrm{~g}}$ transition which are consistent with square planar stereochemistry around the nickel(II) ion. It can be explained with the planar ligand set causes one of the d-orbitals $\left(d x^{2}-y^{2}\right)$ to the uniquely high in energy and the eight electrons can occupy the other four $\mathrm{d}$ orbitals but leave this strongly antibonding one vacant. The visible spectrum of copper complex shows two absorption bands at $654 \mathrm{~nm}$ and $516 \mathrm{~nm}$ assignable to ${ }^{2} \mathrm{~B}_{1 \mathrm{~g}} \rightarrow{ }^{2} \mathrm{~B}_{2 \mathrm{~g}}$ and ${ }^{2} \mathrm{~B}_{1 \mathrm{~g}} \rightarrow{ }^{2} \mathrm{E}_{\mathrm{g}}$ transitions respectively, which indicates the possibility of square planar geometry of the copper complexes. The magnetic moment at $1.74 \mathrm{BM}$, confirms the square planar geometry around copper complex ${ }^{21,22}$.

The copper(II) ion, with $\mathrm{d}^{9}$ configuration, has an effective spin of $\mathrm{S}=1 / 2$ and is associated with a spin angular momentum, $\mathrm{m}_{\mathrm{s}}= \pm 1 / 2$ leading to a doubly degenerate spin state in the absence of a magnetic field. In a magnetic field the degeneracy is lifted between these states and the energy difference between them is given by $\mathrm{E}=\mathrm{h} v=\mathrm{g} \beta \mathrm{H}$, where $\mathrm{h}$ is Planck's constant, $v$ is the microwave frequency for transition from $m_{s}=+1 / 2$ to $m_{s}=-1 / 2$, g is the Lande splitting factor (equal to 2.0023 for a free electron), $\beta$ is the Bohr magneton and $\mathrm{H}$ is the magnetic field. In the case of $3 \mathrm{~d}^{9}$ copper(II) ion, the appropriate Spin Hamiltonian assuming a $\mathrm{B}_{1 \mathrm{~g}}$ ground state is given by

$$
\hat{\mathrm{H}}=\beta\left[\mathrm{g}_{\|} \mathrm{Hz} \mathrm{Sz}+\mathrm{g}_{\perp}(\mathrm{Hx} \mathrm{Sx}+\mathrm{Hy} \mathrm{Sy})+\mathrm{A}_{\|} \mathrm{Iz} \mathrm{Sz}+\mathrm{A}_{\perp}(\mathrm{Ix} \mathrm{Sx}+\mathrm{IySy})\right]
$$

The electron paramagnetic resonance spectrum of polycrystalline sample shows similar features at room temperature (RT) and at liquid nitrogen temperature (LNT). Basic spectral features at both temperatures are same with slightly better resolution at LNT. The $g=2$ signal for both the complexes are broad and nearly isotropic. This is suggestive of the presence of spin -spin interaction, which may be only intermolecular interaction arising due to solid effect. The x- band EPR spectra of the copper(II) complex has been shown in Figure 5.

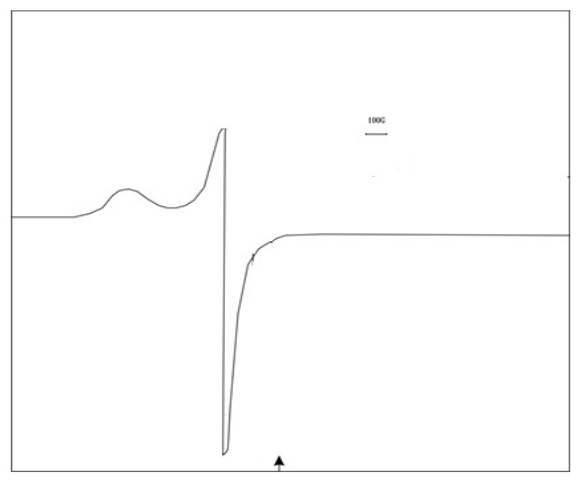

Figure 5. EPR spectrum of complex III

The copper hyperfine features could not be resolved due to intermolecular interactions in the solid state. The trend of the present complex $\left(\mathrm{g}_{\|}>\mathrm{g}_{\perp}>2.03\right)$ was observed indicated that unpaired electron most likely reside in the $\mathrm{dx}^{2}-\mathrm{y}^{2}$ (or less likely a $\mathrm{d}_{\mathrm{xy}}$ ) ground state $^{23}$ which is consistent with the proposed square based geometry (Table 3: EPR spectral parameters of $\mathrm{Cu}(\mathrm{II})$ complex). It has been shown that $\mathrm{g} \|$ is a moderately sensitive function for indicating covalency ${ }^{24}$. Both the complexes $g_{\|}<2.3$ was observed, which indicates a fair degree of covalent character in the $\mathrm{Cu}-\mathrm{L}$ bonding. The geometric parameter $\mathrm{G}$, which is a 
measure of the exchange interaction between the copper centers in the polycrystalline compound, is calculated using the equation: $\mathrm{G}=\left(\mathrm{g}_{\|}-2.0023\right) /\left(\mathrm{g}_{\perp}-2.0023\right)$ for axial spectra and for rhombic spectra $\mathrm{G}=\left(\mathrm{g}_{3}-2\right) /\left(\mathrm{g}_{\perp}-2\right)$ and $\mathrm{g}_{\perp}=\left(\mathrm{g}_{1}+\mathrm{g}_{2}\right) / 2$. If the value of $\mathrm{G}>4$ exchange interaction is negligible, while $\mathrm{G}<4$ indicates considerable exchange interaction in solid complexes ${ }^{25}$.

Table 3. EPR spectral parameters of $\mathrm{Cu}(\mathrm{II})$ complex

\begin{tabular}{ccccc}
\hline Complex & $\mathrm{g}_{\|}$ & $\mathrm{g}_{\perp}$ & $\mathrm{g}_{0}{ }^{\mathrm{a}}$ & $\mathrm{G}^{\mathrm{b}}$ \\
\hline III & 2.236 & 2.089 & 2.138 & 2.695 \\
\hline \multicolumn{4}{c}{${ }^{a} g_{0}=1 / 3\left(g_{\|}+2 g_{\perp}\right)^{b} G=\left(g_{\|}-2.0023\right) /\left(g_{\perp}-2.0023\right)$}
\end{tabular}

\section{Molecular modeling studies}

The molecular geometry of complexes was optimized by molecular mechanics $\left(\mathrm{MM}^{+}\right)$and semi empirical method (PM3) using HyperChem professional version. Molecular mechanics attempts to reproduce molecular geometries, energy and other features by adjusting bond length, bond angles and torsion angles to equilibrium values that are dependent on the hybridization of an atom and its bonding scheme. In order to obtain estimates of structural details of the complexes, we have optimized the molecular structure of complexes (Figure 6a-b: Optimized structure of complexes along with bond length) Energy minimization was repeated several times to find the global minimum. The energy minimization values for the square planar and without restricting the structure for the metal complexes are almost same. The binding energy $(\mathrm{kcal} / \mathrm{mol})$ and Heat of formation $(\mathrm{kcal} / \mathrm{mol})$ of complexes are shown in Table 4. The Complex I has greater binding energy than complex II followed by complex III, also indicates similar trend of heat of formation.

Table 4. The binding energy and heat of formation of complexes

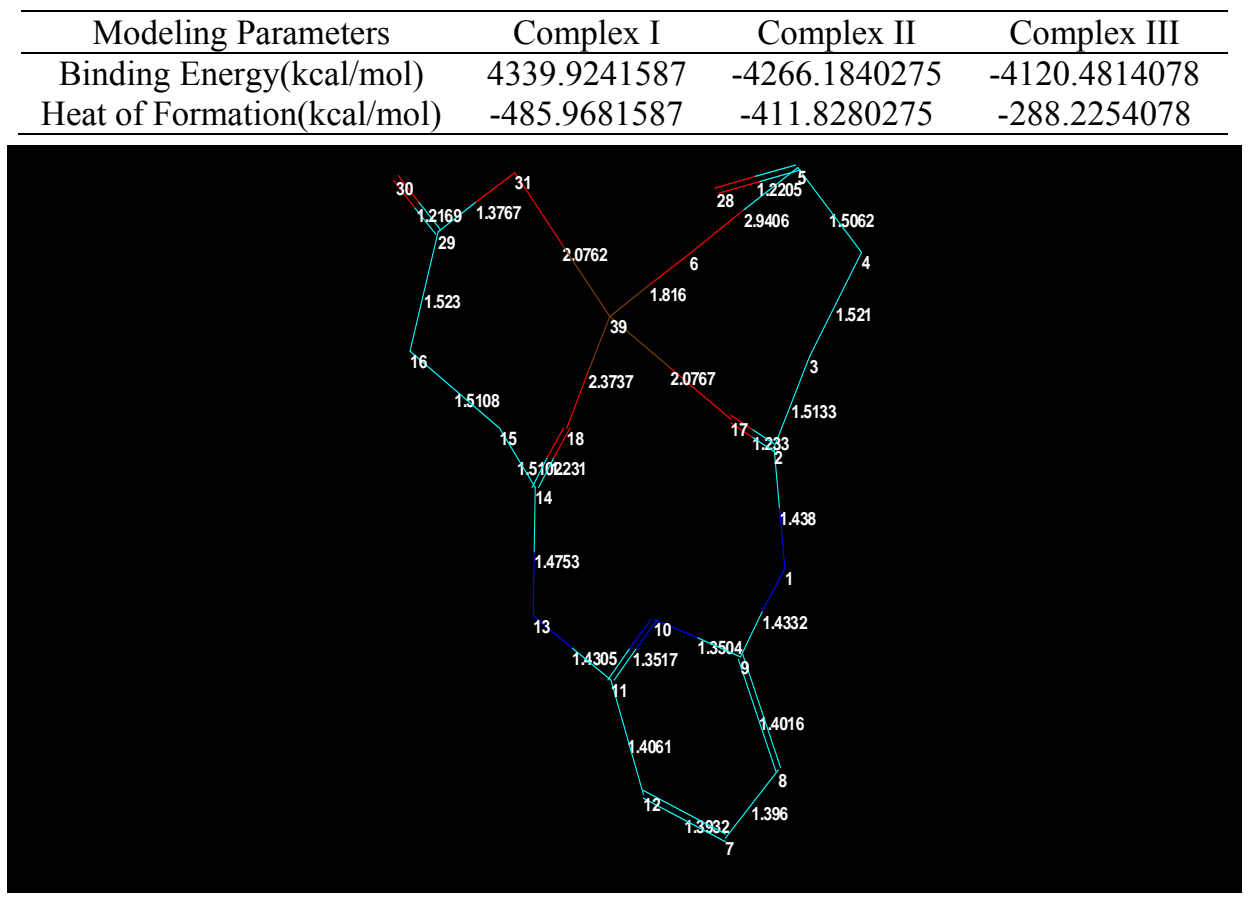

Figure 6a. Optimized structure of complex I 


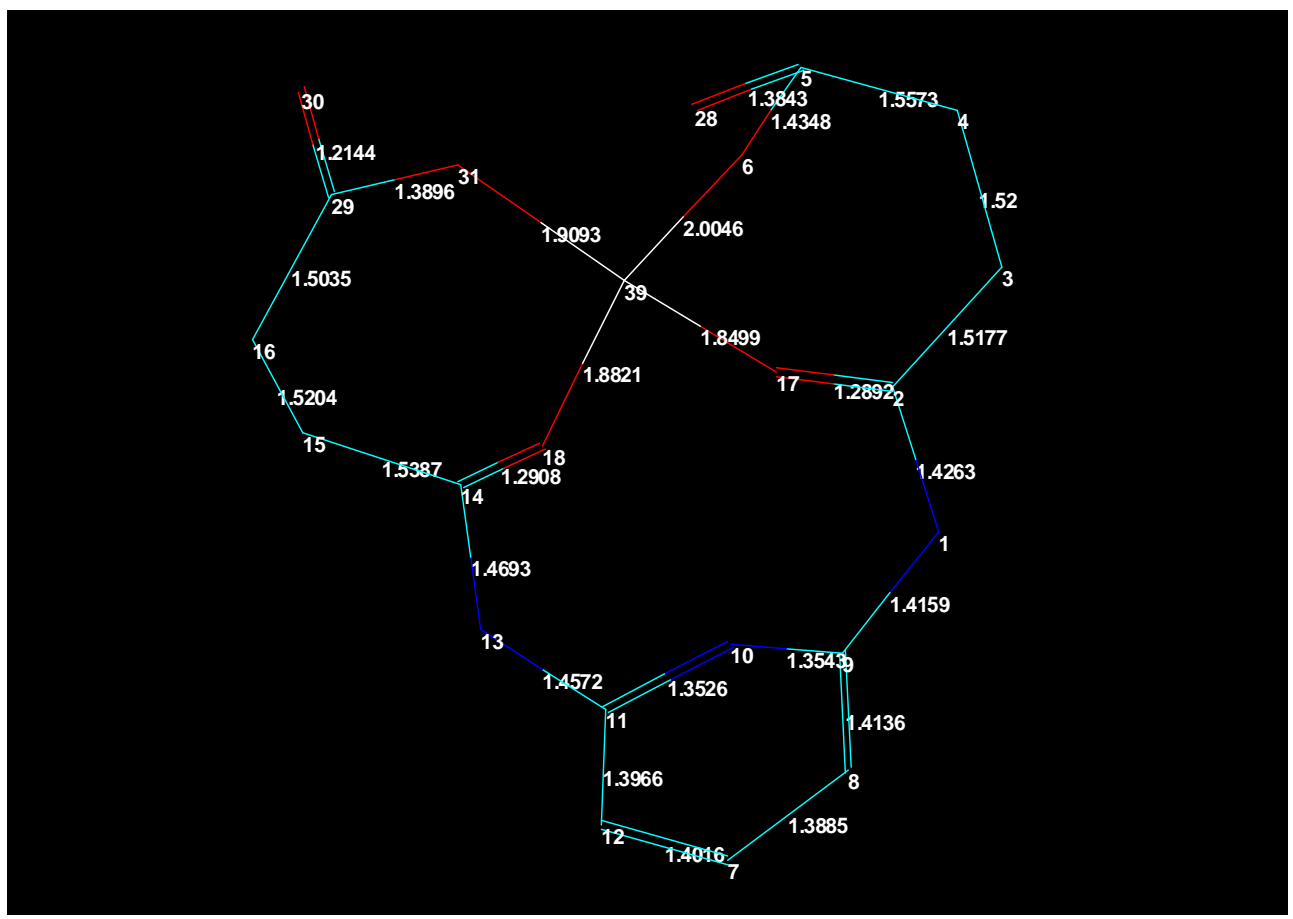

Figure 6b. Optimized structure of complex II

\section{Antibacterial studies}

The free ligands and its respective metal complexes were screened against Streptococcus, Staph, Staphylococcus aureus and Escherchia coli bacteria to assess their potential antibacterial agents. The results are quite promising. The bacterial screening results reveal that the free ligand showed the maximum activity against staphylococcus aureus bacteria followed by Escherchia coli bacteria. The antimicrobial data reveal that the complexes are more bioactive than the free ligands (Figure 7: Antibacterial screening of ligand and its metal complexes). The nickel (II) and copper(II) complexes of ligand showed the maximum activity against Escherchia coli bacteria whereas the cobalt(II) complex showed the maximum activity against Streptococcus bacteria. In general, the activity was the least against Staph bacteria. The activity of any compound is a complex combination of steric, electronic and pharmacokinetic factors. A possible explanation for the toxicity of the complexes has been postulated in the light of chelation theory. The presence of nitrogen and oxygen donor groups in the ligand and its metal complexes inhibited enzyme production because enzymes that require free hydroxyl group for their activity appear to be especially susceptible to deactivation by the metal ion of complexes. Chelation reduces the polarity of the central ion from partial sharing of its positive charge with the donor groups; $\pi$ - electron delocalization in this chelating ring also increases the lipophilic nature of the central atom, favoring permeation through the lipid layer of the membrane ${ }^{26}$. It was also noted that the toxicity of the metal complexes increases on increasing the metal ion concentration. It is probably due to faster diffusion of the chelates through the cell membrane or due to the chelation theory. The bounded metal may block enzymatic activity of the cell or else it may catalyze toxic reactions among cellular constituents. 


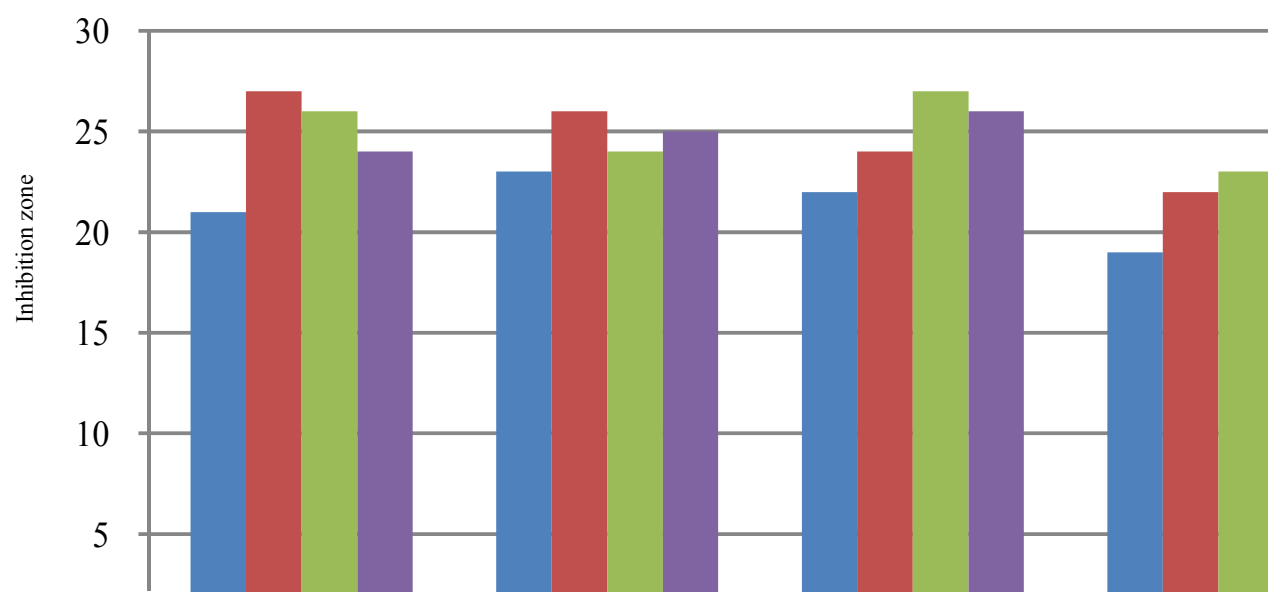

Figure 7. Antibacterial screening of Ligand and its complexes

\section{Conclusion}

Newly synthesized bioactive carboxyamide ligand $N, N^{\prime}$-bis(2-carboxy-1-oxophenelenyl) pyridine 2,6-diamine acts as bidentate chelating agent coordinates with transition metal ions through carboxylate oxygen and carbonyl group of the amide ligand to give square planar environments. The metal chelates possess reasonable antimicrobial potential.

\section{Acknowledgement}

Author(B K Singh) thankfully acknowledge University Grants Commission, New Delhi for financial assistance under Major Research Project.

\section{References}

1. (a) Petering D H, Bynes R W and Antholine W E, Chem Biol Interact., 1990, 73(2-3), 133-182; DOI:10.1016/0009-2797(90)90001-4; (b) Stubbe J and Kozarich J W, Chem Rew., 1987, 87(5), 1107-1136; DOI:10.1021/cr00081a011; (c) Hecht S M, Acc Chem Res., 1986, 19(12), 383-391; DOI:10.1021/ar00132a002; (d) Sigura Y, Takita T and Umezawa H, Met Ions Biol Syst., 1985, 19, 81-108.

2. Metal Amide Chemistry, Ed., by Lappert M, Protchenko A, Power P and Seeber A, 2009, John Willy \& Sons.

3. (a) Proteolytic Enzymes, Beynon R and Bond J S, Eds., $2^{\text {nd }}$ Ed., 2001, Oxford University Press, New York; (b) Jubert C, Mohamadou A, Gerard C, Brandes S, Tabard A and Barbier J P, Inorg Chem Commun., 2003, 6(7), 900-907; DOI:10.1016/S1387-7003(03)00139-4

4. (a) Milovic M N and Kostic N M, J Am Chem Soc., 2003, 125, 781-788; DOI:10.1021/ja027408b; (b) Shi Chun-Yue, Gao En-Jun, Ma S, Wang Mei-Lin and Liu Qi-Tao, Bioorg Med Chem Lett., 2010, 20(24), 7250-7254; DOI:10.1016/j.bmcl.2010.10.097

5. (a) Liang Q, Eason P D and Long E C, J Am Chem Soc., 1995, 117(38), 9625-9631; DOI:10.1021/ja00143a002; (b) Footer M, Egholm M, Kron S, Coull J M and Matsudaira P, Biochem., 1996, 35(33), 10673-10679; DOI:10.1021/bi960486p; (c) Clement O, Rapko B M and Hay B P, Coord Chem Rev., 1998, 170(1), 203-243; DOI:10.1016/S0010-8545(98)00066-6;(d) Belda O and Moberg C, Coord Chem Rev., 
2005, 249(5-6), 727-740; DOI:10.1016/j.ccr.2004.08.025; (e) Singh A P, Kaushik N $\mathrm{K}$, Verma A and Gupta K R, Indian J Chem., 2011, 50A, 474-483.

6. (a) Lee D N, Ryu J Y, Kwak H, Lee Y M, Lee S H, Poong J I, Lee J, Shin W, Kim C, Kim S J and Kim Y, J Mol Struct., 2008, 885(1-3), 56-63; DOI:10.1016/j.molstruc.2007.10.006; (b) Amiri A, Amirnasr M, Meghdadi S, Mereiter K, Ghodsi V and Gholami A, Inorg Chim Acta, 2009, 362(11), 3934-3940; DOI:10.1016/j.ica.2009.05.020; (c) Meghdadi S, Amirnasr M, Habibi M H, Amiri A, Ghodsi V, Rohani A, Harrington R W and Clegg W, Polyhedron, 2008, 27(13), 2771-2778; DOI:10.1016/j.poly.2008.05.031; (d) He X Q, Lin Q W, Hu R D and Lu X H, Spectro Chim Acta A: Mole Biomoler Spectros., 2007, 68(1), 184-192; DOI:10.1016/j.saa.2006.11.012; (e) Zhang J Y, Ke X K, Tu C, Lin J, Ding J, Lin L P, Fun H K, You X Z and Guo Z J, Biometals, 2003, 16(3), 485-496; DOI:10.1023/A:1022577420708; (f) Neveron J C, Lah M S, DelSesto R E, Arif A M, Miller J S and Stang P J, J Am Chem Soc., 2002, 124(23), 6613-6625; DOI:10.1021/ja0200241

7. Jubert C, Mohamadou A, Gerard C, Brandes S, Tabard A and Barbier Jean-Pierre, $J$ Chem Soc, Dalton Trans., 2002, 2660-2669.

8. (a) Perez Y, Johnson A L and Raithby P R, Polyhedron, 2011, 30(2), 284-292; DOI:10.1016/j.poly.2010.10.012; (b) Malone J F, Murray C M, Dolan G M, Docherty R and Lavery A J, Chem Mater., 1997, 9(12), 2983-2989; DOI:10.1021/cm970350t

9. (a) Mitsui K, Hyatt S A, Turner D A, Hadad C M and Parquette J R, Chem Commun., 2009, 3261-3283; DOI:10.1039/B902960E; (b) Chaves F A, Rowland J M, Olmstead M M and Mascharak P K, J Am Chem Soc., 1998, 120(35), 9015-9027; DOI:10.1021/ja9814873

10. (a) Yang T, Zhang J Y, Tu C, Lin J, Liu Q and Guo Z J, Wuji Huaxue Xuebao, 2003, 19, 45; (b) Zhang J, Liu Q, Duan C, Shao Y, Ding J, Miao Z, You X Z and Guo Z, J Chem Soc Dalton Trans., 2002, 591-597.

11. (a) Garg B S, Sarabhai M and Kumar D N, Indian J Chem., 2003, 42A, 275; (b) Singh B K, Bhojak N, Mishra P and Garg B S, Spectrochim Acta A: Mole Biomoler Spectros., 2008, 70(4), 758-765; DOI:10.1016/j.saa.2007.09.008

12. Saxena C, Sharma D K and Singh R V, Phosphorous Sulfur Silicon, 1993, 85(1-4), 9-16; DOI:10.1080/10426509308038176

13. (a) Swamy S J, Veerapratap B, Nagaraju D, Suresh K and Someshwar P, Tetrahedron, 2003, 59(50), 10093-10098; DOI:10.1016/j.tet.2003.09.091; (b) Silvertein R M and Webster F X, Spectrometric Identification of Organic Compound, Sixth Ed., 2007, Wiley India

14. (a) Mohamed G G, Omar M M and Hindy M M, Spectrochim Acta A: Mole Biomoler Spectros., 2005, 62(4-5), 1140-1150; DOI:10.1016/j.saa.2005.03.031; (b) Weyhermuller T, Weighardt K and Chaudhuri P, J Chem Soc., Dalton Trans., 1998, 3805-3813.

15. (a) Weirsema A K and Windle J J, J Phy Chem., 1964, 68, 3216; (b) Garg B S, Kumar D N and Sarbhai M, Spectrochim Acta A: Mole Biomol Spectros., 2005, 61(1-2), 141-147; DOI:10.1016/j.saa.2004.04.007

16. (a) Kabanos T A and Tsangaris J M, J Coord Chem., 1984, 13(2), 89-103; DOI:10.1080/00958978408079760; (b) Nonoyama M, Yamasaki K, Inorg Chim Acta, 1969, 3, 585-690; DOI:10.1016/S0020-1693(00)92556-8; (c) Barnes D J, Chapman R L, Stephens F S and Vagg R S, Inorg Chim Acta, 1981, 51, 155-162; DOI:10.1016/S0020-1693(00)88333-4 
17. Nakamoto K, Infrared and Raman Spectra of Inorganic and Coordination compounds, $3^{\text {rd }}$ Edition, 1978, Wiley, New York.

18. (a) Sanmartin J, Novio F, Garcia- Deibe A M, Fondo M, Ocampo N and Bermejo M R, Polyhedron, 2006, 25(8), 1714-1722; DOI:10.1016/j.poly.2005.11.030; (b) Singh B K, Rajour H K and Prakash A, Spectrochim Acta A: Mole Biomol Spectros., 2012, 94, 143-161; DOI:10.1016/j.saa.2012.03.077

19. (a) Yoshida N, Oshio H and Ito T, J Chem Soc Perkin Trans., 1999, 2, 975-984;

(b)Yoshida N, Ichikawa K and Shiro M J, Chem Soc Parkin Trans., 2000, 2, 17-26; DOI:10.1039/A908041D

20. Abd-Elzaher M M, J Chin Chem Soc., 2001, 48(2), 153-158;

DOI:10.1002/jccs.200100027

21. Nakamoto K and McCarthy S J, Spectroscopy and Structure of Metal Chelate Compounds, John Wiley and Sons, USA, 1968.

22. Figgis B N, Introduction to Ligand Fields, First Ed, 1966, 263.

23. (a) Lever A B P and Mantovani E, Inorg Chem., 1971, 10(4), 817-826; DOI:10.1021/ic50098a031; (b) Murali M, Palaniandavar M and Pandiyan T, Inorg Chim Acta, 1994, 224(1-2), 19-25; DOI:10.1016/0020-1693(94)04009-5

24. Kivelson D and Neiman R, J Chem Phy., 1961, 35, 149.

25. (a) Procter I M, Hathaway B J and Nicholis P, J Chem Soc A, 1968, 1678; DOI:10.1039/J19680001678; (b) Dudley R J and Hathway B J, J Chem Soc A, 1970, 1725; DOI:10.1039/J19700001725; (c) Hathaway B J, J Chem Soc, Dalton Trans., 1972, 1196-1199; DOI:10.1039/DT9720001196

26. Ahamad T, Nishat N and Parveen S, J Coord Chem., 2008, 61(12), 1963-1972; DOI:10.1080/00958970701795698 